\title{
RP-HPLC METHOD FOR THE ESTIMATION OF ZILEUTON IN TABLET FORMULATION
}

\author{
Romana Mahivish ${ }^{1}$, Manjunath SY ${ }^{1}$, Hemant Kumar T ${ }^{*}{ }^{2}$ \\ ${ }^{1}$ Department of Pharmaceutical Analysis, Srikrupa Institute of Pharmaceutical Sciences, Siddipet- \\ 502277 (TS), India \\ ${ }^{*}$ Head, Department of Pharmaceutical Analysis, Srikrupa Institute of Pharmaceutical Sciences \\ Siddipet-502 277 (TS), India
}

DOI: https://doi.org/10.29121/granthaalayah.v9.i1.2021.2276

Article Type: Research Article

Article Citation: Romana Mahivish, Manjunath SY, and Hemant Kumar T. (2021). RP-HPLC METHOD FOR THE ESTIMATION OF ZILEUTON IN TABLET FORMULATION. International Journal of Research GRANTHAALAYAH, 9(1), 141-149. https://doi.org/10.29121/granthaa layah.v9.i1.2021.2276

Received Date: 01 November 2020

Accepted Date: 31 December 2021

Keywords:

Zileuton

RP-HPLC

Tablet Dosage Form

\section{ABSTRACT}

A simple, rapid, accurate and precise RP-HPLC method was developed and validated for the determination of zileuton in table dosage form. Chromatographic analysis of the drug was achieved on Cyberlab HPLC comprising of LC- 100P pump, a variable wavelength programmable LCUV100 UV detector and SCL system controller. Flowrosil C18 column (250 $\mathrm{mm} \times 4.6 \mathrm{~mm}, 5 \mu$ ) as stationary phase with mobile phase consisting of Methanol: Acetonitrile: 1\% GAA in the ratio of 70:10:20 v/v. The method showed a good linear response in the concentration range of $5-30 \mu \mathrm{g} / \mathrm{ml}$ with correlation coefficient of 0.9993 . The flow rate was maintained at 1.0 $\mathrm{ml} / \mathrm{min}$ and detection was carried out at $230 \mathrm{~nm}$. The retention time was $3.12 \mathrm{~min}$. The method was statistically validated for accuracy, precision, linearity, ruggedness, robustness, solution stability, selectivity and sensitivity. The results obtained in the study were within the limits of ICH guidelines and hence this method can be used for the determination of zileuton in tablet formulation.

\section{INTRODUCTION}

Zileuton [R, S $( \pm$ ) N-(1-(benzo [b]-thien-2-yl) ethyl)-N-hydroxyurea] (Fig. 1) is a racemic mixture having approximately equal therapeutic activities which selectively and reversibly inhibits 5-lypoxygenase potentiating leukotrienes (LT's - $\mathrm{LTA}_{4}, \mathrm{LTB}_{4}, \mathrm{LTC}_{4}, \mathrm{LTD}_{4}$ and $\mathrm{LTE}_{4}$ ); mostly indicated in inflammatory diseases akin to psoriasis, rheumatoid arthritis, asthma, multi-ple sclerosis, uveitis and inflammatory bowel syndrome [1]. Zileuton is a very slightly soluble compound without any ionizable functional group. Zileuton is used for the prophylaxis and chronic treatment of asthma in adults and children 12 years of age and older. Contraindications are active liver disease or resistant elevation in transaminase at least 3 times the history of allergic reactions to zileuton or any of its inactive ingredients. Zileuton is a minor substrate of CYP1A2, 2C8/9, 3A4, and a weak inhibitor of CYP 1A2[2]. The drug has been shown to increase the serum concentration or effects of theophylline, propranolol and warfarin, although significant increase in prothrombin time is not obvious. It is advised that the doses of each medication be monitored and/or reduced accordingly. Literature survey reveals analytical methods reported for estimation of zileuton in API, pharmaceutical dosage form and biological fluid includes spectrophotometry [3],[4],[5],[6],[7],[8],[9],[10], RP-HPLC [11],[12],[13] and LC-MS [14],[15]. Obviously, HPLC methods [16],[17] are superior in compared to

(C) 2021 The Author(s). This is an open access article distributed under the terms of the Creative Commons Attribution License, which permits unrestricted use, distribution, and reproduction in any medium, provided the original author and source are credited. 
spectrophotometric methods in terms of accuracy and sensitivity. The reported HPLC methods available for quantification of zileuton have a drawbacks of long retention times and not completely validated. As long retention time need a more consumption of mobile phase. So, there is a need of a HPLC method, where the retention time is less.

The purpose of this study was to develop a simple, rapid, precise, and accurate RP-HPLC method for the estimation of zileuton in tablet dosage form.

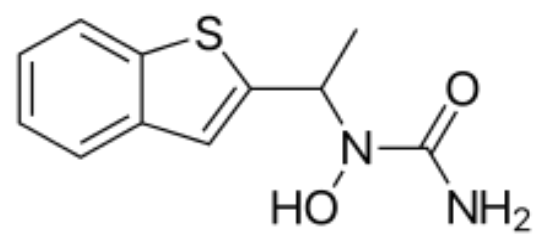

Figure 1: Structure of Zileuton

\section{MATERIALS AND METHODS:}

\section{Instrumention}

Chromatographic separation was performed on a Cyberlab HPLC system equipped with a Flowrosil C18 column $(250 \times 4.6 \mathrm{~mm}$, with $5 \mu \mathrm{m}$ particle), single pumps, variable wave length detector and Rheodyne injector with $20 \mu \mathrm{l}$ loop volume. 'LC solution' software was used to collect and process the data. Ultra sonicator (Citizen ultra sonicator) was used for sonicating the drug and sample solution. Digital weighing balance (SHIMADZU AUX 220) used for weighing. ELICO SL 244 double beam UV-VIS spectrophotometer.

\section{Materials}

Zileuton raw material was obtained from Yarrow Chem. products, Mumbai, India. Tablet formulation GRILUTOCR (Cadila Healthcare Limited, Goa, India) containing Zileuton $600 \mathrm{mg}$ was purchased from local pharmacy. All reagents and solvents used were analytical grade. Double distilled water was obtained from a millipore purification unit. HPLC grade Methanol was obtained from Merck life science Pvt Ltd, HPLC grade Acetonitrile was obtained from Merck life science Pvt Ltd.

\section{Preparation of Mobile phase}

Mobile phase was prepared by mixing $700 \mathrm{~mL}$ of HPLC grade methanol, $100 \mathrm{ml}$ of HPLC grade acetonitrile and $200 \mathrm{~mL}$ of $1 \%$ Glacial acetic acid (prepared by mixing $2 \mathrm{ml}$ of glacial acetic acid in $200 \mathrm{ml}$ of of HPLC grade water). The mobile phase was sonicated for $10 \mathrm{~min}$ and filtered through the $0.45 \mu \mathrm{m}$ membrane filter.

\section{Preparation of standard stock solutions}

The standard stock solutions of $100 \mu \mathrm{g} / \mathrm{mL}$ of the drug were prepared by dissolving $50 \mathrm{mg}$ of pure drug in the mobile phase in a $50 \mathrm{~mL}$ volumetric flask and the volume was made up to the mark with mobile phase. Resulting solutions were further diluted with mobile phase to obtain a final concentration of $100 \mu \mathrm{g} / \mathrm{mL}$ and stored under refrigeration. Aliquots of standard stock solutions were put in a $10 \mathrm{~mL}$ volumetric flask and diluted up to the mark with mobile phase. In such a way, the final concentrations of the drug were in the range of 5-30 $\mu \mathrm{g} / \mathrm{mL}$.

\section{Preparation of sample solution}

To determine the content of zileuton in tablet dosage form (Label claim: $600 \mathrm{mg} / \mathrm{tablet}$ ) ten tablets were accurately weighed and triturated to fine powder. The powder weight equivalent to $100 \mathrm{mg}$ of zileuton was taken and dissolved in $100 \mathrm{ml}$ of mobile phase. The solution was sonicated for few minutes and filtered through $0.22 \mu$ membrane filter. Form the resulting solution ( $1 \mathrm{ml}$ ) was transferred to a $10 \mathrm{ml}$ volumetric flask and diluted up to the mark with mobile phase. From this $2 \mathrm{ml}$ was transferred to a $10 \mathrm{ml}$ volumetric flask and diluted up to the mark with mobile phase. A $20 \mu \mathrm{L}$ of the filtrate was injected into chromatographic system. The peak area of the zileuton was determined and concentration was found using linear regression equation obtained from calibration curve. 


\section{Chromatographic conditions}

The chromatographic system used for method development and validation includes the LC-P100 pump, variable wavelength programmable LC-UV100 UV detector and SCL20A system controller at CYBERLAB HPLC. A Rheodyne injector 7725i equipped with a $20 \mu \mathrm{L}$ loop was used and the data was recorded and evaluated using LC solution software version 5.0. Separation was performed at Flowrosil C18 $(250 \times 4.6 \mathrm{~mm}$ i.d., $5 \mu \mathrm{m})$ at the ambient temperature. A mixture of Methanol: Acetonitrile: 1\% GAA in the ratio of 70:10:20 v/v was found to be the ideal mobile phase for the ideal chromatographic analysis of zileuton. The solvent mixture was filtered through a $0.22 \mu$ membrane filter and sonicated before use. It is pumped through the column at a flow rate of $1.0 \mathrm{~mL} / \mathrm{min}$. The injection volume is maintained in the column at $20 \mu \mathrm{L}$ and room temperature. The column was balanced by pumping the mobile phase through the column for at least 20 min before injecting the drug solution. The detection was monitored at $230 \mathrm{~nm}$. Run time is set to 10 minutes. Optimized chromatographic conditions are shown in Table 1.

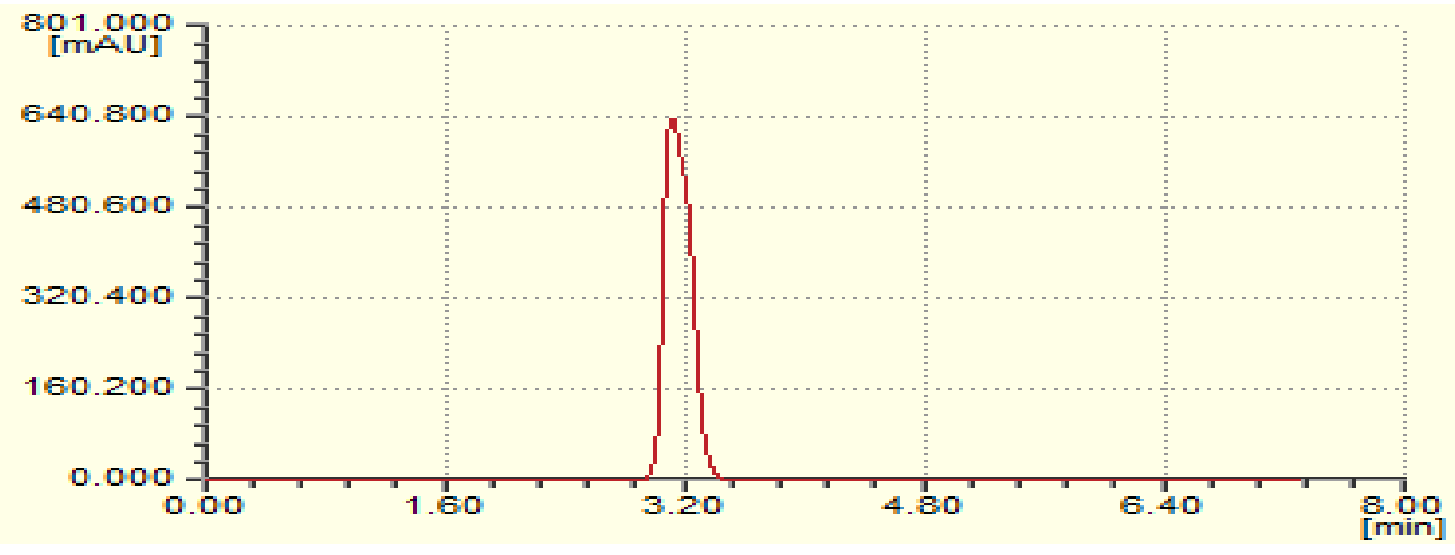

Figure 2: Chromatogram of standard solution of zileuton

Table 1: Optimized chromatographic conditions

\begin{tabular}{|c|c|}
\hline Parameters & Conditions \\
\hline Stationary Phase (Column) & $\mathrm{C}_{18}(250 \times 4.6 \mathrm{~mm}$ i.d., $5 \mu)$ \\
\hline Mobile Phase & Methanol: Acetonitrile: $1 \% \mathrm{GAA}(70: 10: 20 \mathrm{v} / \mathrm{v})$ \\
\hline Flow rate $(\mathrm{ml} / \mathrm{min})$ & $1.0 \mathrm{~mL} / \mathrm{min}$ \\
\hline Run time(min) & $10 \mathrm{~min}$ \\
\hline Column temperature $\left({ }^{\circ} \mathrm{C}\right)$ & Ambient \\
\hline Volume of injection loop $(\mu \mathrm{L})$ & 20 \\
\hline Detection wavelength $(\mathrm{nm})$ & $230 \mathrm{~nm}$ \\
\hline Retention time(min) & 3.12 \\
\hline
\end{tabular}

\section{Method Validation}

The developed method was validated as per ICH guidelines ${ }^{26}$ by evaluating linearity, accuracy, precision, robustness, ruggedness, detection limit, quantification limit and stability. Coefficients of variation and relative errors of less than $2 \%$ were considered acceptable.

\section{System Suitability Test}

Before performing validation experiments, system suitability test (SST) has to be applied to indicate that HPLC system and method are capable of providing data with admissible quality. SST was performed by investigating capacity factor, tailing factor, theoretical plates number, and also relative standard deviation (RSD) of the peak areas.

\section{Stability}

Stability was assessed by analyzing QC standard solutions after keeping them at room temperature for $48 \mathrm{~h}$. Obtained results were investigated as recovery values and compared to the freshly prepared solutions. 


\section{Linearity}

A stock solution of zileuton of $1000 \mu \mathrm{g} / \mathrm{mL}$ was prepared with mobile phase. From it, various working standard solutions were prepared in the range of 5 to $50 \mu \mathrm{g} / \mathrm{ml}$ and injected into HPLC. It was shown that the selected drug had linearity in the range of 5-30 $\mu \mathrm{g} / \mathrm{mL}$. The calibration plot (peak area of zileuton versus zileuton concentration) was generated by replicate analysis $(n=6)$ at all concentration levels and the linear relationship was evaluated using the least square method within Microsoft Excel® program.

\section{Accuracy}

The accuracy of the method was carried out using one set of different standard addition methods at different concentration levels, $50 \%, 100 \%$ and $150 \%$, and then comparing the difference between the spiked value (theoretical value) and actual found value.

\section{Precision}

The precision of the method was ascertained from the peak area obtained by actual determination of six replicates of a fixed amount of the drug $(20 \mu \mathrm{g} / \mathrm{mL})$. The precision of the assay was also determined in terms of intraand inter-day variation in the peak areas of a set of drug solutions on three different days. The intra- and inter-day variation in the peak area of the drug solution was calculated in terms of relative standard deviation (RSD).

\section{Robustness}

Robustness of the proposed method for zileutone was carried out by the slight variation in flow rate, analytical wavelength and mobile phase ratio. The percentage recovery and RSD were noted for zileutone.

\section{Ruggedness}

The test solutions were prepared as per test method and injected under variable conditions. Ruggedness of the method was studied by different analysts.

\section{Detection limit and quantification limit}

The limit of detection (LOD) and limit of quantification (LOQ) were established based on the calibration curve parameters, according to the following formulas:

$\mathrm{LOD}=3.3 \mathrm{SD} /$ slope

$\mathrm{LOQ}=10 \mathrm{SD} /$ slope

or detection limit $=3.3 \sigma / \mathrm{s}$, quantification limit $=10 \sigma / \mathrm{s}$, where $\sigma$ is the standard deviation of $y$-intercept of regression line, and so is the slope of the calibration curve.

\section{Specificity}

The specificity of the proposed method was determined against blank and placebo applications. Here mobile phase was used as blank and excipients like starch, lactose, magnesium stearate were used as placebo.

\section{RESULTS AND DISCUSSION}

\section{Method validation}

\section{System Suitability Test}

After setting the optimum conditions, system suitability parameters for the developed method were determined and compared with recommended limits. To determine the parameters, the study was performed with standard solution of $50 \mu \mathrm{g} / \mathrm{ml}$ concentration and the results were acquired from six injections. System suitability parameters of the method were demonstrated in Table 2. According to the results, all of the system suitability parameters were within the recommended limits and the method was found to be suitable for the analysis.

Table 2: Results of system suitability test $(n=6)$

\begin{tabular}{|c|c|c|}
\hline Parameter & Criteria & Result \\
\hline Capacity factor $(k)$ & $k^{\prime}>2$ & 3.824 \\
\hline
\end{tabular}




\begin{tabular}{|c|c|c|}
\hline Tailing factor $(T)$ & $\mathrm{T}<2$ & 1.15 \\
\hline Theoretical plates $(N)$ & $\mathrm{N}>2000$ & 4320 \\
\hline \% RSD (peak area) & $\%$ RSD $\leq 1$ & 0.74 \\
\hline
\end{tabular}

\section{Stability}

The sample solution stability was analyzed by injecting the same solution at $0,12,24$, and $48 \mathrm{~h}$. Identical change was not observed in the developed method. Also, results were found within acceptable limits ( $\%$ RSD $<2$ ), which are summarized in Table 3.

Table 3: Stability data of zileuton (standard solutions)

\begin{tabular}{|c|c|c|}
\hline Time (hr) & Assay (\%) & \% Difference \\
\hline Initial & 100.08 & ---- \\
\hline After $12 \mathrm{hr}$ & 100.02 & 0.05 \\
\hline After $24 \mathrm{hr}$ & 99.87 & 0.21 \\
\hline After $36 \mathrm{hr}$ & 99.16 & 0.92 \\
\hline After $48 \mathrm{hr}$ & 98.32 & 1.76 \\
\hline
\end{tabular}

\section{Linearity and sensitivity}

Linearity study was performed with calibration standards with $5,10,15,20,25$ and $30 \mu \mathrm{g} / \mathrm{ml}$ concentrations. The standards were injected in triplicate. Calibration curves were obtained by plotting the peak areas against the given concentrations. The calibration curve was evaluated by the determination coefficient. The determination coefficient $\left(R^{2}\right)$ of the calibration curves was 0.9993 . Therefore, the calibration curve for zileutone was found to be linear within the range of $5-30 \mu \mathrm{g} / \mathrm{ml}$ concentrations as shown in Fig.3. The regression equations were calculated from the calibration graphs. The sensitivity of the analytical method was evaluated by determining the limits of detection (LOD) and quantitation (LOQ). The values of LOD and LOQ are given in Table 4. The low values of LOD and LOQ indicates the sensitivity of method.

Table 4: Spectral and statistical data for determination of Zileuton by proposed RP-HPLC method.

\begin{tabular}{|c|c|}
\hline Parameter & Result \\
\hline Detection wavelength $(\mathrm{nm})$ & 230 \\
\hline Linearity range $(\mu \mathrm{g} / \mathrm{ml})$ & $5-30$ \\
\hline Coefficient of determination $\left(r^{2}\right)$ & 0.9984 \\
\hline Regression equation $\left(Y^{\mathrm{a}}\right)$ & $\mathrm{Y}=16025 \mathrm{x}+20911$ \\
\hline Slope $(\mathrm{m})$ & 16025 \\
\hline Intercept $(\mathrm{c})$ & 20911 \\
\hline Limit of detection, LOD $(\mu \mathrm{g} / \mathrm{ml})$ & 0.03 \\
\hline Limit of quantitation, $\mathrm{LOQ}(\mu \mathrm{g} / \mathrm{ml})$ & 0.12 \\
\hline
\end{tabular}

a $Y=m x+c$, where $x$ is the concentration $(\mu \mathrm{g} / \mathrm{ml})$.

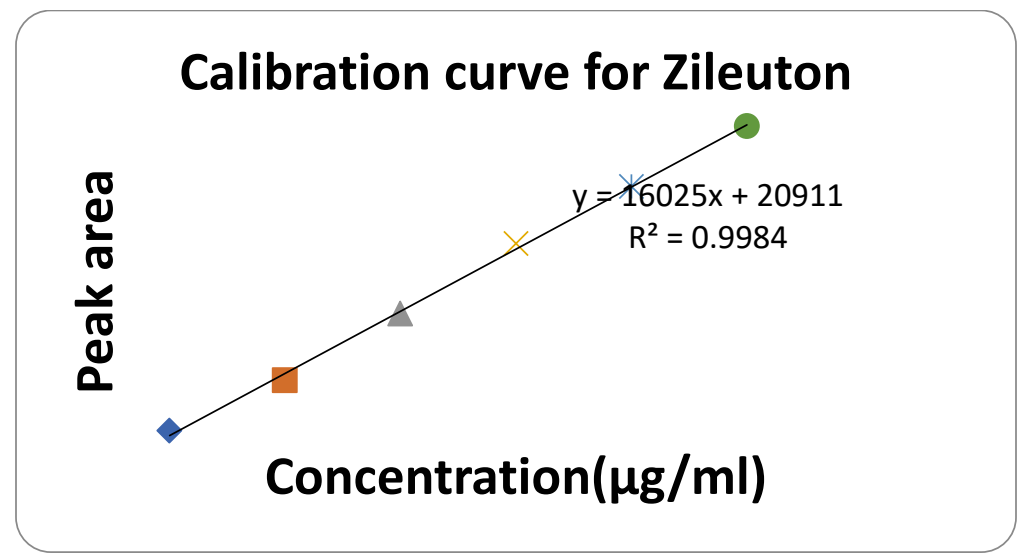

Figure 3: Calibration curve of zileuton 


\section{Accuracy}

To study the reliability, the suitability, and the accuracy of the method, recovery experiments were carried out. Known quantities of the pure drug were added to the preanalyzed sample to make samples at the levels of $50 \%, 100$ $\%$, and $150 \%$, and were assayed by the proposed method. Accuracy was calculated as the percentage of recovery. The recovery and relative standard deviation for each of the analytes are given Table 5 . From the recovery studies it is evidence that the method is highly accurate and can give excellent results.

Table 5: Accuracy results

\begin{tabular}{|c|c|c|c|c|c|c|}
\hline \multirow{2}{*}{ \% Level } & \multicolumn{2}{|c|}{ Concentration $(\mu \mathrm{g} / \mathrm{mL})$} & \multirow{2}{*}{ Recovery (\%) } & \multicolumn{3}{|c|}{ Statistical Results } \\
\cline { 2 - 3 } & Formulation & Pure drug & & Mean & SD & $\%$ RSD \\
\hline 50 & 20 & 10 & 98.4 & & & \\
50 & 20 & 10 & 98.1 & 99.1 & 0.87 & 0.88 \\
50 & 20 & 10 & 100.8 & & & \\
\hline 100 & 20 & 20 & 100.5 & & & \\
100 & 20 & 20 & 101.9 & 101.3 & 0.12 & 0.10 \\
100 & 20 & 20 & 98.8 & & & \\
\hline 150 & 20 & 30 & 99.4 & & & \\
150 & 20 & 30 & 99.7 & 99.8 & 0.51 & 0.52 \\
150 & 20 & 30 & 100.4 & & & \\
\hline
\end{tabular}

\section{Precision}

The precision was demonstrated at three levels: repeatability, intermediate precision, and reproducibility (between laboratories' precision). Each level of precision was investigated by 3 sequential replicates of injections of three concentrations of 10, 20 and $30 \mu \mathrm{g} / \mathrm{mL}$. The precision was expressed as relative standard deviation (RSD) or coefficient of variation (CV). The results of three levels of precision are shown in Table 6. The developed method was found to be precise as the RSD values for repeatability, intermediate precision and reproducibility studies were $<2$ $\%$, respectively as recommended by ICH guidelines (ICH Q2 (R1), 2005).

Table 6: Precision results

\begin{tabular}{|c|c|c|c|}
\hline \multirow{2}{*}{ Precision } & \multicolumn{3}{|c|}{ Results } \\
\cline { 2 - 4 } & Concentration $(\mu \mathrm{g} / \mathrm{mL})$ & \% RSD of Peak area & \% RSD of Retention Time \\
\hline Repeatability & 10 & 0.69 & 0.08 \\
& 20 & 1.81 & 0.02 \\
& 30 & 1.51 & 0.17 \\
\hline Intermediate precision & 10 & 1.72 & 0.18 \\
& 20 & 0.89 & 0.06 \\
& 30 & 0.77 & 0.07 \\
\hline Reproducibility & 10 & 1.91 & 0.31 \\
& 20 & 0.88 & 0.32 \\
& 30 & 0.71 & 0.06 \\
\hline
\end{tabular}

\section{Robustness and ruggedness}

Robustness of the method was studied by deliberate variations of the analytical parameters such as flow rate $(1.0 \pm 0.1 \mathrm{~mL} / \mathrm{min})$, mobile phase composition ( $\pm 5 \%$ organic phase) and analytical wavelength $( \pm 2 \mathrm{~nm})$. The results are given in Tables 7. The result shown that have the negligible effect on retention time, recoveries and peak area of zileutone indicating the developed method is robust. Ruggedness of the method was carried out by different analysts. The results are displayed in Table 8. There is no variation in peak areas and retention time of zileutone from studies carried out by two analysts as indicated by $\%$ RSD $<2$ gives the method rugged. 
Romana Mahivish, Manjunath SY, and Hemant Kumar T

Table 7: Robustness studies

\begin{tabular}{|c|c|c|c|c|c|}
\hline \multirow{2}{*}{ Parameter } & Variation & \multicolumn{4}{|c|}{ Observed value } \\
\cline { 3 - 6 } & & \% RSD of area & \% RSD of R. T & Tailing factor & Theroteical plates(N) \\
\hline Flow rate & 0.9 & 0.47 & 0.09 & 1.14 & 4312 \\
& 1.1 & 0.65 & 0.07 & 1.15 & 4325 \\
\hline M.Phase & $75 \%$ methanol & 0.79 & 0.04 & 1.14 & 4387 \\
Composition & $65 \%$ methanol & 0.81 & 0.13 & 1.14 & 4365 \\
\hline Wavelength & $232 \mathrm{~nm}$ & 0.66 & 0.07 & 1.13 & 4321 \\
& $228 \mathrm{~nm}$ & 0.92 & 0.02 & 1.14 & 4307 \\
\hline
\end{tabular}

Table 8: Ruggedness studies

\begin{tabular}{|c|c|c|c|c|}
\hline \multirow{2}{*}{ Analyst } & \multicolumn{4}{|c|}{ Observed value } \\
\cline { 2 - 5 } & \% RSD of area & \% RSD of R. T & Tailing factor(T) & Theroteical plates(N) \\
\hline Analyst I & 0.45 & 0.07 & 1.15 & 4386 \\
\hline Analyst II & 0.52 & 0.06 & 1.15 & 4311 \\
\hline
\end{tabular}

\section{Mobile phase stability}

The stability of the mobile phase was evaluated, so the mobile phase was stored at $4-8{ }^{\circ} \mathrm{C}$ for 1 week. The aged mobile phase was compared using a freshly prepared one. The mobile phase was stable up to 1 week at $4-8{ }^{\circ} \mathrm{C}$.

\section{Specificity}

Specificity is the ability to unequivocally assess the analyte in the presence of components that may be expected to be present. Typically, these might include impurities, degradants or matrix. Specificity of an analytical method is its ability to accurately and specifically measure the analyte of interest without interference from blank or placebo. The peak purity of Zileuton was assessed by comparing the retention times of standard zileutone and the sample, and good correlation was obtained between the retention time of the standard and sample. Placebo and blank were injected and there were no peaks. There is no interference of blank and placebo on drug peaks hence, the method is specific.

\section{Sample Analysis}

The developed and validated method was applied for analysis of tablet formulation contain zileutone. The sample was analyzed in triplicate. Analysis results were evaluated using a calibration curve. The amount of zileutone in the samples was calculated from calibration curve equation and recovery and RSD values were determined. The results of analysis are given in Table 9. The recoveries were in good agreement with the label claims. The chromatogram obtained were clear as shown in Fig. 6. It was concluded that the method can be applied successfully for the analysis of zileutone in tablet dosage form

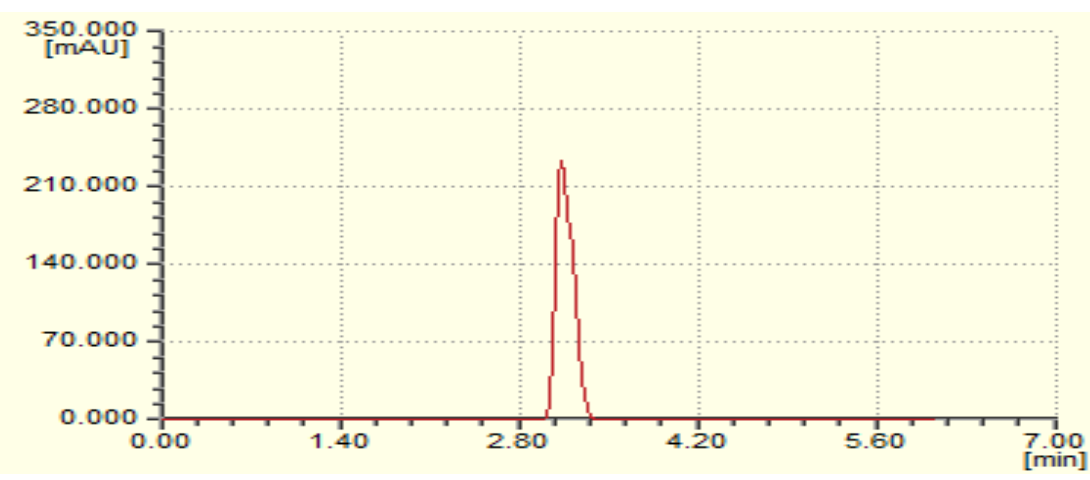

Figure 4: Chromatogram of zileuton sample solution 
RP-HPLC Method for The Estimation of Zileuton In Tablet Formulation

Table 9: Assay results from commercial formulation

\begin{tabular}{|c|c|c|c|}
\hline Sample & Labelled amount(mg) & Amount obtained* $(\mathrm{mg})$ & Percentage Recovery* \pm SD \\
\hline $\begin{array}{c}\text { GRILUTO-CR tablets } \\
\text { (Zileutone) }\end{array}$ & 600 & 598.92 & $99.82 \pm 0.92$ \\
\hline
\end{tabular}

* Average of five determinations

\section{CONCLUSION}

The proposed method for the estimation of zileuton was validated as per the ICH guidelines and it is simple, specific and reliable. Furthermore, this simple and rapid RP-HPLC method can also be used successfully for the determination of zileutone in pharmaceutical formulations without any interference from the excipient.

\section{SOURCES OF FUNDING}

This research received no specific grant from any funding agency in the public, commercial, or not-for-profit sectors.

\section{CONFLICT OF INTEREST}

The author have declared that no competing interests exist.

\section{ACKNOWLEDGMENT}

Authors are thankful to the Management of Srikrupa Institute of Pharmaceutical Sciences for providing necessary laboratory facilities for carrying out this work.

\section{REFERENCES}

[1] Rask-Madson J, Buckhave K, Laursen LS, Lauritsen K.5-Lipoxygenase inhibitors for the treatment of inflammatory bowel disease. Agents and Actions.1992; 36:37-46.

[2] Zouboulis CC. Zileuton, a new efficient and safe systemic anti-acne drug. Dermato-Endocrinology. 2009; 1:188-192.

[3] Kumar AK, Nareshbabu N. Development and Validation of Analytical method for the Estimation of Zileuton in Bulk and in Pharmaceutical dosage forms by UV Spectroscopy. International Research Journal of Pharmacy. 2012; 3:154-157.

[4] Romana Mahivish, Manjunath SY and Hemant Kumar. UV spectrophotometric method for estimation of zileuton in pharmaceutical formulation. GSC Biological and Pharmaceutical Sciences, 2020, 13(01), 212-219.

[5] Ganorkar SB, Shirkhedkar AA, Dhumal DM. Application of UV-spectrophotometry for determination of zileuton in bulk and in tablets. Indian Drugs, 2013; 50: 40-43.

[6] Vara KPR, Tanuja M, Rao YS, Kumar HT. Development and Validation of Stability Indicating UV Spectrophotometric Method for The Estimation of Zileuton In Bulk and Tablet Dosage Form. International Journal of Pharmacy, 2015; 5(2) :393-397.

[7] Kumar HT, Rao KVP, Tanuja, Rao YS. Validated visible spectrophotometric methods for determination of Zileuton in pharmaceutical formulation. International Journal of Pharmacy. 2015; 6: 397-405.

[8] Rao KVP, Tanuja, Rao YS, Kumar HT. Development and Validation of Spectrophotometric Methods for Estimation of Zileuton In Bulk and Its Dosage Form. International Journal of Chemical Sciences. 2015; 13(2): 714-724.

[9] Ganorkar SB, Shirkhedkar AA. Novel HPTLC and UV-AUC analyses: For simple, economical, and rapid determination of Zileuton racemate. Arabian Journal of Chemistry. 2017; 10: 360-367.

[10] Rao KVP, Tanuja M, Rao YS, Kumar TH. Visible spectrophotometric methods for determination of zileuton in bulk drug and pharmaceutical formulation. International Journal of Research in Pharmacy and Chemistry. 2015; 5(2) :251-257. 
[11] Shirkhedkar AA, Ganorkar SB, Dhumal DM (2017) Development and validation of simple RP-HPLC-PDA analytical protocol for zileuton assisted with Design of Experiments for robustness determination. Arabian Journal of Chemistry. 2017; 10: 273-282.

[12] Rao KVP, Tanuja M, Rao YS, Kumar TH. Development and Validation of RP-HPLC method for the estimation of Zileuton in bulk and its dosage form. International Journal of Drug Development \& Research. 2015; 7(1) :101106.

[13] Granneman GR, Braeckman RA, Erdman KA. Determination of a new 5-lipoxygenase inhibitor, zileuton, and its inactive $\mathrm{N}$-dehydroxylated metabolite in plasma by high performance liquid chromatography. Clinical Pharmacokinetics, 1995; 29: 1-8.

[14] Prakash K, Adiki SK, Kalakuntla RR (2014) Development and validation of a liquid chromatography mass spectrometry method for the determination of zileuton in human plasma. Scientia Pharmaceutica. 2014; 82:571-583.

[15] Pian P, Labovitz E, Hoffman K, Clavijo CF, Lynn RR, Galinkin JL, Vinks AA, Malik P, Christians U. Quantification of the 5-lipoxygenase inhibitor zileuton in human plasma using high performance liquid chromatographytandem mass spectrometry. Journal of Chromatography B. 2013; 937:79-83.

[16] Bhavana V, Hemant TK, Srinivasa YR, Rao KVP. RP-HPLC method for estimation of Solifenacin Succinate in API and Tablet dosage form.Asian Journal of Pharmaceutical Analysis.9(3); 2019:118-122.

[17] Mounika PS, Hemant TK, Srinivasa YR, Rao KVP. RP-HPLC Method for Quantification of Empagliflozin In Pharmaceutical Formulation. Asian Journal of Pharmacy and Technology.9(3); 2019:208-211.

[18] ICH - Guidelines Q2A, Validation of Analytical Procedures: Definition and Terminology (CPMP III/5626/94) March (1995). Geneva, Switzerland: ICH. ICH - Guidelines Q2B, Validation of Analytical Procedures: Methodology, (CPMP/ICH/281/95) November (1996). Geneva, Switzerland: ICH. 